\title{
Bank lending policy, credit scoring and value-at-risk
}

\author{
Tor Jacobson *, Kasper Roszbach \\ Research Department, Sveriges riksbank, 10337 Stockholm, Sweden
}

Received 12 January 2001; accepted 10 September 2001

\begin{abstract}
This paper builds on the credit-scoring literature and proposes a method to calculate portfolio credit risk. Individual default risk estimates are used to compose a value-at-risk (VaR) measure of credit risk. In general, credit-scoring models suffer from a sample-selection bias. The starting point is therefore to estimate an unbiased scoring model using the bivariate probit approach. The paper uses a large data set with Swedish consumer credit data that contains extensive financial and personal information on both rejected and approved applicants. We study how marginal changes in a default-risk-based acceptance rule would shift the size of the bank's loan portfolio, its VaR exposure and average credit losses. Finally, we compare the risk in the sample portfolio with that in an efficiently provided portfolio of equal size. The results show that the size of a small consumer loan does not affect associated default risk, implying that the bank provides loans in a way that is not consistent with default-risk minimization. VaR calculations indicate that an efficient selection (by means of a default-riskbased rule) of loan applicants can reduce credit risk by up to $80 \%$.
\end{abstract}

(c) 2002 Elsevier Science B.V. All rights reserved.

JEL classification: C35; D61; D81; G21; G33

Keywords: Banks; Lending policy; Credit scoring; Credit risk; Value-at-risk; Bivariate probit

\section{Introduction}

Consumer credit has come to play an increasingly important role, both as an instrument in the financial planning of households and as an asset on the balance sheet

\footnotetext{
${ }^{*}$ Corresponding author. Tel.: +46-8-787-000; fax: +46-8-210-531.

E-mail addresses: tor.jacobson@riksbank.se (T. Jacobson), kasper.roszbach@riksbank.se (K. Roszbach).
} 
of financial institutions. By the end of 1999, Swedish consumer credit made up 31\% of total lending to the public when excluding residential loans and amounted to the equivalent of $15 \%$ of Swedish GDP, or $29 \%$ of total private consumption. ${ }^{1}$ Consequently, investigating the properties of banks' lending policies is of interest because of both the "household channel" and the "financial market channel". Despite the increasing importance of consumer credit, it is common to see households being rationed in financial markets. ${ }^{2}$ When rationing is the mechanism that allocates resources in credit markets, some applicants will be excluded from credit despite being equally creditworthy as those granted a loan, making the equilibrium that results inefficient. Since a lender cannot observe borrowers' probabilities of default, credit-scoring models - by enabling a lending institution to rank potential customers according to their default risk - can improve the allocation of resources, from a second best towards the first best equilibrium.

In practice, most credit-scoring models suffer from a sample-selection bias because they are estimated from a sample of granted loans and the criteria by which applicants are rejected are not taken into account. ${ }^{3}$ Boyes et al. (1989) avoided this bias by designing a bivariate probit model with two sequential events as the dependent variables: the lender's decision to grant the loan or not, and - conditional on the loan having been provided - the borrower's ability to pay it off or not. Boyes et al. used their unbiased credit-scoring model to examine the provision of credit by banks and found that it takes place in a way that is not consistent with default-risk minimization. 4

The contribution of this paper is to augment the usage of credit-scoring models. We propose that individual estimates of default risk be used to compose a measure of credit-risk exposure resembling the value-at-risk (VaR) concept. The paper shows how such a risk measure can be constructed for a portfolio of loans and presents two problems to which it can be applied. A value-weighted, instead of an unweightedsum, of all individual default risks is a more suitable measure of the risk in a portfolio of loans for a financial institution to consider when it needs to balance risk and return.

\footnotetext{
${ }^{1}$ The results in Sections 3 and 4 of this paper are based on a sample of Swedish consumer loans. See Section 2 for a description of the data.

${ }^{2}$ Several different definitions of credit rationing exist. Here, we have in mind the unequal treatment of ex-ante equal people due to an asymmetry in information sets. Jaffee and Stiglitz (1990), Stiglitz and Weiss (1981) and Williamson (1987) discuss some different definitions and explanations of this phenomenon.

${ }^{3}$ Presumably, the main reason for this deficiency is the lack of publicly available data on rejected loan applicants. In Sweden, for example, banks are only allowed to store data on rejected loan applicants for commercial purposes for a period of three months. Banks can obtain a special permit to store reject data for analytical purposes from the Swedish Data Inspection Board.

${ }^{4}$ In a bivariate probit model, variables that increase (decrease) the probability of positive granting decision should reduce (raise) the likelihood of a default. Boyes et al. (1989) found that coefficients for variables like duration of job tenure, education and credit-card ownership carried equal signs in both equations. In addition, unexplained tendencies to extend credit, as measured by the regression error, were positively correlated with default frequencies. Both observations are inconsistent with a policy of defaultrisk minimization.
} 
A natural starting point is to estimate an unbiased credit-scoring model, i.e., the bivariate-probit model. For this purpose, a large data set is used that contains extensive financial and personal information on the loan applicants, both rejected and approved. Next, we take VaR as the relevant risk measure and study how marginal changes in a default-risk-based acceptance rule would shift the size of the bank's loan portfolio, its VaR exposure and average credit losses. Finally, the risk in the sample portfolio is compared with that of an efficiently provided portfolio of equal size. This shows that an important risk-reducing property of an unbiased credit-scoring model works through the selection of different applicants.

The paper is organized as follows: Section 2 describes the data set and its sources. Section 3 presents and discusses the parameter estimates of the econometric model. Section 4 puts the empirical estimates to further use in the above mentioned VaR experiments. Section 5 provides a summary of the results and some concluding remarks.

\section{Data}

The data set consists of 13,338 applications for a loan at a major Swedish lending institution between September 1994 and August 1995. All loans were granted in stores where potential customers applied for instant credit to finance the purchase of a consumer good. The evaluation of each application took place in the following way. First, the store phoned the lending institution to get an approval or a rejection. The lending institution then analyzed the applicant with the help of a database with personal characteristics and credit variables to which it has on-line access. The database is maintained by Upplysningscentralen AB, the leading Swedish credit bureau which is jointly owned by all Swedish banks and lending institutions. If approval was granted, the store's salesperson filled out a loan contract and submitted it to the lending institution. The loan is revolving and administered by the lending institution as any other credit facility. It is provided in the form of a credit card that can only be used in a specific store. Some fixed minimum payment by the borrower is required in each month. However, since the loan is revolving, there is no predetermined maturity of the loan. Earnings on the loan come from three sources: a one-time fee paid by the customer; a payment by the store that is related to total amount of loans granted through it; and interest on the balance outstanding on the card.

For this study, the lending institution provided us with a data file with the personal number of each applicant, the date on which the application was submitted, the size of the loan that was granted, the status of each loan (good or bad) on 9 October 1996, and the date on which bad loans gained this status.

Although one can think of several definitions of a "bad loan", we classify a loan as bad once it is forwarded to a debt-collection agency. We do not study what factors determine the differences in loss rates, if any, among bad loans. An alternative definition of the set of bad loans could have been "all customers who have received one, two or three reminders because of delayed payment". However, unlike "forwarded to debt-collecting agency", one, two or three reminders were all transient states in 
the register of the financial institution. Once customers returned to the agreed-upon repayment scheme, the number of reminders was reset to zero. Such a property is rather undesirable if one needs to determine unambiguously which loans have defaulted and which have not.

Upplysningscentralen provided the information that was available on each applicant at the time of application and which the financial institution accessed for its evaluation. By exploiting the unique personal number that each resident of Sweden has, the credit bureau was able to merge these two data sets. Before handing over the combined data for analysis, the personal numbers were removed.

The database included publicly available, governmentally supplied information, such as sex, citizenship, marital status, postal code, taxable income, taxable wealth, house ownership, and variables reported by Swedish banks like the total number of inquiries made about an individual, the number of unsecured loans and the total amount of unsecured loans. In total we disposed of 57 variables. Table 1 contains definitions for the variables that have been selected for the estimation of the empirical model in Section 3. Of the 57 variables, 41 were not used in the final estimation of the model described in Sections 3 and 4. Most were disregarded because they lacked a univariate relation with the variables of interest - the loan granting decision and the payment behavior-or displayed extremely high correlation with another

Table 1

Definition of variables

\begin{tabular}{|c|c|}
\hline Variable & Definition \\
\hline AGE & age of applicant \\
\hline MALE & dummy, takes value 1 if applicant is male \\
\hline DIVORCE & dummy, takes value 1 if applicant is divorced \\
\hline HOUSE & dummy, takes value 1 if applicant owns a (possibly mortgaged) house. \\
\hline BIGCITY & $\begin{array}{l}\text { dummy, takes value } 1 \text { if applicant lives in one of the three greater metropolitan } \\
\text { areas around Göteborg, Malmö and Stockholm. }\end{array}$ \\
\hline NRQUEST & $\begin{array}{l}\text { number of requests for information on the applicant that the credit agency received } \\
\text { during the last } 36 \text { months }\end{array}$ \\
\hline ENTREPR & dummy, takes value 1 if applicant has taxable income from a registered business \\
\hline INCOME & $\begin{array}{l}\text { annual income from wages as reported to Swedish tax authorities in } 1993 \text { or } 1994 \\
\text { (depending on granting date) (in SEK 1000) }\end{array}$ \\
\hline DIFINC & $\begin{array}{l}\text { change in annual income from wages, relative to preceding year, as reported to } \\
\text { Swedish tax authorities (in SEK 1000) }\end{array}$ \\
\hline CAPINC & dummy, takes value 1 if applicant has taxable income from capital \\
\hline BALINC & $\begin{array}{l}\text { ratio of total collateral-free credit facilities actually utilized and INCOME, } \\
\text { expressed as percentage. }\end{array}$ \\
\hline ZEROLIM & dummy, takes value 1 if applicant has no collateral-free loans outstanding \\
\hline LIMIT & total amount of collateral-free credit facilities already outstanding (in 1000 SEK) \\
\hline NRLOANS & number of collateral-free loans already outstanding \\
\hline LIMUTIL & percentage of LIMIT that is actually being utilized \\
\hline LOANSIZE & amount of credit granted (in 1000 SEK) \\
\hline COAPPLIC & dummy, takes value 1 if applicant has a guarantor \\
\hline
\end{tabular}

The table contains only the variables that were selected for the final estimation of model (1).

${ }^{\mathrm{a}}$ This variable is defined as DUMMY $\left.\mathrm{Sincome}>0\right\} *(\mathrm{BALANCE} / \mathrm{INCOME})$. 
variable that measured approximately the same thing but had greater (univariate) explanatory power. Most of these were tax-related variables or income components. Several variables that passed the univariate tests were not significant in either the loan-granting or the default equation in any of the estimations. ${ }^{5}$ Citizenship, all immigration-related variables and real estate value were among these.

Finally, wealth up to SEK 900,000 (US\$90,000) is tax-exempted, making the group of people with taxable wealth extremely small in Sweden. Since not a single bad loan concerned a person with positive taxable wealth, one cannot use taxable wealth as an explanatory variable without creating a numerical problem in the gradient of the likelihood function. Therefore, taxable income from capital - which is taxed from the first krona-was used to create a dummy explanatory variable.

Table 2 contains descriptive statistics for the variables used in the empirical model in Section 3. Of all applicants, 6899 or $51.7 \%$, were refused credit. The remaining 6439 obtained a loan ranging from 3000 to 30,000 Swedish kronor (US\$3003000). The lending institution's policy was that no loans exceeding 30,000 kronor were supplied. Although there is an indicated amortization scheme, the loans have no fixed maturity - they are revolving.

Table 2

Descriptive statistics for all loan applicants $(N=13,338)$

\begin{tabular}{|c|c|c|c|c|c|c|c|c|}
\hline \multirow[t]{2}{*}{ Variable } & \multicolumn{4}{|c|}{ Rejections $(N=6899)$} & \multicolumn{4}{|c|}{ Granted loans $(N=6439)$} \\
\hline & Mean & Stdev & Min & $\operatorname{Max}$ & Mean & Stdev & Min & Max \\
\hline AGE & 38.65 & 12.76 & 18 & 84 & 41.02 & 12.08 & 20 & 83 \\
\hline MALE & 0.62 & 0.48 & 0 & 1 & 0.65 & 0.48 & 0 & 1 \\
\hline DIVORCE & 0.13 & 0.34 & 0 & 1 & 0.14 & 0.35 & 0 & 1 \\
\hline HOUSE & 0.34 & 0.47 & 0 & 1 & 0.47 & 0.50 & 0 & 1 \\
\hline BIGCITY & 0.41 & 0.49 & 0 & 1 & 0.37 & 0.48 & 0 & 1 \\
\hline NRQUEST & 4.69 & 2.60 & 1 & 10 & 4.81 & 2.68 & 1 & 19 \\
\hline ENTREPR & 0.04 & 0.21 & 0 & 1 & 0.02 & 0.16 & 0 & 1 \\
\hline INCOME & 129.93 & 70.38 & 0 & 737.9 & 189.47 & 75.70 & 0 & 1093.0 \\
\hline DIFINC & 5.37 & 34.06 & -438.5 & 252.6 & 9.03 & 34.63 & -6226 & 5006.0 \\
\hline CAPINC & 0.12 & 0.32 & 0 & 1 & 0.07 & 0.25 & 0 & 1 \\
\hline BALINC $^{a}$ & 91.04 & 894.53 & 0 & 41533 & 31.01 & 386.15 & 0 & 22387 \\
\hline BALINC $^{b}$ & 114.01 & 999.73 & 1 & 41533 & 35.85 & 431.87 & 1 & 22387 \\
\hline ZEROLIM & 0.15 & 0.36 & 0 & 1 & $<0.01$ & 0.05 & 0 & 1 \\
\hline LIMIT & 79.89 & 93.69 & 0 & 1703.0 & 50.47 & 51.07 & 0 & 949.2 \\
\hline NRLOANS & 2.99 & 2.42 & 0 & 18 & 3.65 & 2.04 & 0 & 16 \\
\hline LIMUTIL & 64.34 & 38.88 & 0 & 278.0 & 53.22 & 33.94 & 0 & 124.0 \\
\hline COAPPLIC & 0.16 & 0.36 & 0 & 1 & 0.14 & 0.35 & 0 & 1 \\
\hline
\end{tabular}

The table contains only the variables that were selected for the final estimation of model (1).

${ }^{a}$ Computed for the 6508 rejected and 6372 approved applications with INCOME $>0$

${ }^{\mathrm{b}}$ Computed for the 5197 rejected and 5086 approved applications with BALINC $>0$.

\footnotetext{
${ }^{5}$ We tested all reasonable variable permutations.
} 
On 9 October 1996, the people in the sample were monitored by the lending institution. On that day $388(6.0 \%)$ of those who obtained a loan had defaulted and been forwarded to a debt collection agency. All other borrowers still fulfilled their minimum repayment obligations at that time. Some descriptive statistics are provided in Table 3.

In addition to the descriptive statistics provided in Tables 2 and 3, a formal test for equality in means and variances could enhance our understanding of the mechanisms at work in the model to be estimated in Sections 3 and 4. At least for the loan-granting equation (to be discussed in Section 3), significant differences in means can be expected to translate into significant parameters in the policy equation. As far as the default behavior is concerned, the relation between significant differences in means and significant parameter estimates is only indirect. As a consequence of the sample-selection effect, the model's parameters of default behavior depend on those of the loan granting policy.

The magnitudes of estimated means and corresponding standard errors in Table 2 imply that a formal test for differences in means between the two groups of granted and rejected applicants will not yield significant test statistics for any variable. The same is true for the two groups of good and bad loans in Table 3. But the absence of any significant differences in means does not, of course, preclude that the entire distributions of the explanatory variables differ between groups. To formalize this,

Table 3

Descriptive statistics for granted loans

\begin{tabular}{|c|c|c|c|c|c|c|c|c|}
\hline \multirow[t]{2}{*}{ Variable } & \multicolumn{4}{|c|}{ Defaulted loans $(N=388)$} & \multicolumn{4}{|c|}{ Good loans $(N=6051)$} \\
\hline & Mean & Stdev & Min & Max & Mean & Stdev & Min & $\operatorname{Max}$ \\
\hline $\mathrm{AGE}$ & 36.11 & 11.03 & 21 & 75 & 41.33 & 12.07 & 20 & 83 \\
\hline MALE & 0.67 & 0.47 & 0 & 1 & 0.65 & 0.48 & 0 & 1 \\
\hline DIVORCE & 0.20 & 0.40 & 0 & 1 & 0.14 & 0.35 & 0 & 1 \\
\hline HOUSE & 0.28 & 0.45 & 0 & 1 & 0.48 & 0.50 & 0 & 1 \\
\hline BIGCITY & 0.41 & 0.49 & 0 & 1 & 0.36 & 0.48 & 0 & 1 \\
\hline NRQUEST & 6.15 & 2.85 & 1 & 14 & 4.72 & 2.64 & 1 & 19 \\
\hline ENTREPR & 0.02 & 0.13 & 0 & 1 & 0.03 & 0.16 & 0 & 1 \\
\hline INCOME & 165.36 & 82.35 & 0 & 1093.0 & 191.01 & 75.00 & 0 & 1031.7 \\
\hline DIFINC & 3.52 & 39.01 & -135.0 & 439.7 & 9.38 & 34.30 & -622.6 & 500.6 \\
\hline CAPINC & 0.04 & 0.20 & 0 & 1 & 0.07 & 0.26 & 0 & 1 \\
\hline BALINC $^{\text {a }}$ & 39.92 & 313.51 & 0 & 6041 & 30.44 & 390.36 & 0 & 22387 \\
\hline BALINC $^{b}$ & 46.45 & 337.81 & 1 & 6041 & 38.33 & 437.68 & 1 & 22387 \\
\hline ZEROLIM & 0.04 & 0.20 & 0 & 1 & $<0.01$ & 0.02 & 0 & 1 \\
\hline LIMIT & 41.44 & 57.98 & 0 & 511.5 & 51.05 & 50.54 & 0 & 949.21 \\
\hline NRLOANS & 2.34 & 1.64 & 0 & 11 & 3.74 & 2.04 & 0 & 16 \\
\hline LIMUTIL & 75.69 & 33.37 & 0 & 124.0 & 51.78 & 33.47 & 0 & 112.0 \\
\hline LOANSIZE & 7.08 & 3.95 & 3.0 & 24.5 & 7.12 & 3.83 & 3.0 & 30.0 \\
\hline COAPPLIC & 0.07 & 0.26 & 0 & 1 & 0.14 & 0.35 & 0 & 1 \\
\hline
\end{tabular}

The table contains only the variables that were selected for the final estimation of model (1).

${ }^{\text {a }}$ Only computed for the 5988 good and 384 bad loans with INCOME $>0$

${ }^{\mathrm{b}}$ Only computed for the 4756 good and 330 bad loans with BALINC $>0$. 
Kolmogorov-Smirnov (K-S) tests have been administered for equality in distribution function for each explanatory variable in Table 1 with respect to (i) granted and rejected applications, and (ii) good loans and bad loans.

Table 4 shows that for 10 variables, including HOUSE, INCOME, DIFINC, LIMIT, NRLOANS, LIMUTIL and BALINC the null is rejected in favor of rejected applicants having a distribution with smaller values. The table, however, also reveals a lack of power for the $\mathrm{K}-\mathrm{S}$ test since the null is also rejected in favor of rejected applicants having a distribution with larger values for three variables, namely LIMIT, LIMUTIL and BALINC. The null of equal distributions is not rejected for merely four variables.

For the subsample of granted loans, the null is rejected in favor of good loans having a distribution with smaller values for NRQUEST, LIMUTIL and BALINC. The null is rejected in favor of good loans having a distribution with larger values for HOUSE, INCOME, DIFINC, LIMIT, NRLOANS, LIMUTIL and BALINC. For the remaining eight variables the $\mathrm{K}-\mathrm{S}$ test supports the null of equal distributions.

Overall, these univariate tests confirm our impression that, between groups, there is a considerable amount of variation in the data. The extent to which univariate

Table 4

$\mathrm{K}-\mathrm{S}$ tests for equality of cdfs

\begin{tabular}{|c|c|c|c|c|c|c|c|c|}
\hline \multirow[t]{3}{*}{ Variable } & \multicolumn{4}{|c|}{ All applicants } & \multicolumn{4}{|c|}{ Granted loans } \\
\hline & \multicolumn{2}{|c|}{ Rej. $<$ Grant } & \multicolumn{2}{|c|}{ Rej. > Grant } & \multicolumn{2}{|c|}{ Good $<$ Bad } & \multicolumn{2}{|c|}{ Good $>$ Bad } \\
\hline & $D$-test & $P$-val & $D$-test & $P$-val & $D$-test & $P$-val & $D$-test & $P$-val \\
\hline $\mathrm{AGE}$ & 0.1059 & 0.000 & -0.0081 & 0.645 & 0.0003 & 1.000 & -0.2018 & 0.000 \\
\hline MALE & 0.0289 & 0.004 & 0.0000 & 1.000 & 0.0176 & 0.797 & 0.0000 & 1.000 \\
\hline DIVORCE & 0.0102 & 0.497 & 0.0000 & 1.000 & 0.0593 & 0.077 & 0.0000 & 1.000 \\
\hline HOUSE & 0.1337 & 0.000 & 0.0000 & 1.000 & 0.0000 & 1.000 & -0.1996 & 0.000 \\
\hline BIGCITY & 0.0000 & 1.000 & -0.0478 & 0.000 & 0.0517 & 0.142 & 0.0000 & 1.000 \\
\hline NRQUEST & 0.0388 & 0.000 & -0.0080 & 0.656 & 0.2121 & 0.000 & -0.0003 & 1.000 \\
\hline ENTREPR & 0.0000 & 1.000 & -0.0200 & 0.071 & 0.0000 & 1.000 & -0.0071 & 0.964 \\
\hline INCOME & 0.3360 & 0.000 & 0.0000 & 1.000 & 0.0040 & 0.988 & -0.1790 & 0.000 \\
\hline DIFINC & 0.0832 & 0.000 & -0.0013 & 0.990 & 0.0036 & 0.990 & -0.1203 & 0.000 \\
\hline CAPINC & 0.0000 & 1.000 & -0.0490 & 0.000 & 0.0000 & 1.000 & -0.0268 & 0.593 \\
\hline BALINC & 0.0366 & 0.000 & -0.3152 & 0.000 & 0.0754 & 0.016 & -0.0040 & 0.988 \\
\hline ZEROLIM & 0.0000 & 1.000 & -0.1497 & 0.000 & 0.0409 & 0.295 & 0.0000 & 1.000 \\
\hline LIMIT & 0.1657 & 0.000 & -0.2084 & 0.000 & 0.0091 & 0.942 & -0.1860 & 0.000 \\
\hline NRLOANS & 0.1925 & 0.000 & -0.0026 & 0.956 & 0.0000 & 1.000 & -0.3176 & 0.000 \\
\hline LIMUTIL & 0.0518 & 0.000 & -0.2574 & 0.000 & 0.4142 & 0.000 & 0.0000 & 1.000 \\
\hline COAPPLIC & 0.0000 & 1.000 & -0.0162 & 0.173 & 0.0000 & 1.000 & -0.0685 & 0.033 \\
\hline LOANSIZE & & & & & 0.0180 & 0.790 & -0.0394 & 0.323 \\
\hline
\end{tabular}

The table contains the results from four tests. Column 1 tests the null hypothesis of equal distributions against the alternative that rejected applicants have smaller values than granted applications, while column 2 tests against the alternative of bigger values. Column 3 tests the null hypothesis of equal distributions against the alternative that good loans have smaller values than bad loans, while column 4 tests against the alternative of bigger values. 
relations will translate into multivariate relationships will be treated in the sections to follow.

\section{Empirical analysis}

\subsection{Econometric model}

In this section, we begin by briefly presenting the bivariate probit model. For details, we refer to Boyes et al. (1989) and references within. The model consists of two simultaneous equations, one for the binary decision to provide a loan or not, $y_{1 i}$, and another for the binary outcome, "default" or "proper repayment", of each loan, $y_{2 i}$. Let the superscript $*$ indicate an unobserved variable and assume that $y_{1 i}^{*}$ and $y_{2 i}^{*}$ follow

$$
\begin{aligned}
& y_{1 i}^{*}=\mathbf{x}_{1 i} \cdot \boldsymbol{\alpha}_{1}+\varepsilon_{1 i}, \\
& y_{2 i}^{*}=\mathbf{x}_{2 i} \cdot \boldsymbol{\alpha}_{2}+\varepsilon_{2 i} \text { for } i=1,2, \ldots, N
\end{aligned}
$$

where the $\mathbf{x}_{j i}, j=1,2$, are $1 \times k_{j}$ vectors of explanatory variables and the disturbances are assumed to be zero-mean, bivariate normal distributed with unit variances and a correlation coefficient $\rho$.

The binary choice variable $y_{1 i}$ takes value 1 if the loan was granted and 0 if the application was rejected:

$$
y_{1 i}= \begin{cases}0 & \text { if loan not granted }\left(y_{1 i}^{*}<0\right) \\ 1 & \text { if loan granted }\left(y_{1 i}^{*} \geqslant 0\right)\end{cases}
$$

The second binary variable, $y_{2 i}$, takes the value 0 if the loan defaults and 1 if not:

$$
y_{2 i}= \begin{cases}0 & \text { if loan defaults }\left(y_{2 i}^{*}<0\right) \\ 1 & \text { if loan does not default }\left(y_{2 i}^{*} \geqslant 0\right) .\end{cases}
$$

Due to the fact that one only observes if a loan is good or bad if it was granted, there is not only a censoring rule for $\left(y_{1 i}, y_{2 i}\right)$ but also an observation rule. This gives rise to three types of observations: no loans, bad loans and good loans. The likelihood function therefore takes the following form:

$$
\ell=\prod_{\text {no loans }} \operatorname{pr}(\text { no loan }) \cdot \prod_{\text {bad loans }} \operatorname{pr}(\text { bad loan }) \prod_{\text {good loans }} \operatorname{pr}(\text { good loan }) .
$$

It can be shown that (3.1) implies the following log likelihood: ${ }^{6}$

\footnotetext{
${ }^{6}$ Details are available upon request and at http://swopec.hhs.se.
} 


$$
\begin{aligned}
\ln \ell= & \sum_{i=1}^{N}\left(1-y_{1 i}\right) \ln \left[1-\Phi\left(\mathbf{x}_{1 i} \boldsymbol{\alpha}_{1}\right)\right] \\
& +\sum_{i=1}^{N} y_{1 i} \cdot\left(1-y_{2 i}\right) \ln \left\{\Phi\left(\mathbf{x}_{1 i} \boldsymbol{\alpha}_{1}\right)-\Phi_{2}\left(\mathbf{x}_{1 i} \boldsymbol{\alpha}_{1}, \mathbf{x}_{2 i} \boldsymbol{\alpha}_{2} ; \rho\right)\right\} \\
& +\sum_{i=1}^{N} y_{1 i} \cdot y_{2 i} \ln \Phi_{2}\left(\mathbf{x}_{1 i} \boldsymbol{\alpha}_{1}, \mathbf{x}_{2 i} \boldsymbol{\alpha}_{2} ; \rho\right),
\end{aligned}
$$

where $\Phi(\cdot)$ and $\Phi_{2}(\cdot, \cdot, \rho)$ represent the univariate and bivariate standard normal cumulative distribution functions, the latter with correlation coefficient $\rho$.

\subsection{Empirical model}

The estimated parameters and their standard errors are presented in Table 5. Notice that LOANSIZE cannot be used as an explanatory variable in the first equation because no data on this variable is available for rejected applicants. The effects of many variables on the probability of obtaining a loan seem in accordance with the behavior banks commonly display. INCOME, HOUSE, ENTREPR, NRLOANS and having a COAPPLICant confirm their role as important factors that contribute positively while ZEROLIM, LIMIT and LIMUTIL weigh negatively in the bank's decision. Somewhat surprising are the coefficients on MALE, BIGCITY, DIFINC and CAPINC. ${ }^{7}$

Boyes et al. (1989) recognized that if banks were minimizing default risk, one should find that variables with a positive (negative) effect on the probability of granting a loan ought to have a negative (positive) effect on default risk in the bivariate probit model. It is striking that in our model only four variables, ZEROLIM, LIMUTIL, NRLOANS and COAPPLIC, have (the default-risk minimizing) equal signs in both equations.

Another four variables have opposite coefficients in the loan granting and default equations and a large number of variables is significant in only one equation. INCOME, AGE, DIFINC and LIMIT, for example, increase (decrease) the probability

\footnotetext{
${ }^{7}$ Men have a significantly smaller chance of being granted a loan as do people living in one of the three metropolitan areas. The same holds for people who have capital income and those who experienced a rise in income during the last year. The latter effect deserves some further attention, though. Another way to interpret the sign of this parameter would be that people who experience large increases in wage income had quite a low income the preceding year. Rather than reasoning that a rise in income worsens your chances of getting a loan, one could argue that income uncertainty - embodied in a low income in the year before - does so. If this were the case, then we should expect a similar effect to exist for people experiencing a fall in income. We tested for the presence of such an effect by transforming DIFINC into a variable with absolute values of income changes. We also tried it with the standard deviation of income. Neither of these variables gained significance. One possible interpretation of the coefficients in INCOME and DIFINC is the following: rewrite $\boldsymbol{\alpha}_{y} y_{t}+\boldsymbol{\alpha}_{\mathrm{d} y} \Delta y_{t}$ as $\left(\boldsymbol{\alpha}_{y}+\boldsymbol{\alpha}_{\mathrm{d} y}\right) y_{t}-\boldsymbol{\alpha}_{\mathrm{d} y} y_{t-1}$. Current and past income then both have positive and significant coefficients in the equation, with the former carrying the largest weight - as in a calculation of permanent income.
} 
Table 5

Bivariate probit MLE of $\widehat{\boldsymbol{\alpha}}_{1}$ and $\widehat{\boldsymbol{\alpha}}_{2}$

\begin{tabular}{|c|c|c|c|c|}
\hline \multirow[t]{2}{*}{ Variable } & \multicolumn{2}{|c|}{$P($ obtain a loan $)$} & \multicolumn{2}{|c|}{$P($ loan does not default $)$} \\
\hline & $\widehat{\boldsymbol{\alpha}}_{1}$ & $t$-stat & $\widehat{\boldsymbol{\alpha}}_{2}$ & $t$-stat \\
\hline CONSTANT & -0.2374 & $-3.57^{* * *}$ & 2.2900 & $15.65^{* * *}$ \\
\hline AGE & -0.004303 & $-3.69^{* * *}$ & 0.006892 & $2.63^{* * *}$ \\
\hline MALE & -0.2003 & $-7.10^{* * *}$ & -0.02456 & -0.43 \\
\hline DIVORCE & -0.02588 & -0.70 & -0.2380 & $-3.34^{* * *}$ \\
\hline HOUSE & 0.06391 & $2.32^{* *}$ & -0.02019 & 0.35 \\
\hline BIGCITY & -0.2382 & $-8.96^{* * *}$ & -0.03724 & -0.69 \\
\hline NRQUEST & -0.008123 & -1.58 & -0.1000 & $-9.84^{* * *}$ \\
\hline ENTREPR & 0.5223 & $8.30^{* * *}$ & 0.2065 & 1.28 \\
\hline INCOME & 0.008928 & $49.17^{* * *}$ & -0.002392 & $-4.81^{* * *}$ \\
\hline DIFINC & -0.002336 & $-6.78^{* * *}$ & 0.002233 & $3.04^{* * *}$ \\
\hline CAPINC & -0.2776 & $-5.48^{* * *}$ & 0.1189 & 0.97 \\
\hline BALINC & 0.00006548 & $3.48^{* * *}$ & -0.00009135 & -1.54 \\
\hline ZEROLIM & -2.244 & $-21.40^{* * *}$ & -0.6590 & $-2.23^{* *}$ \\
\hline LIMIT & -0.008381 & $-54.94^{* * *}$ & 0.005064 & $10.28^{* * *}$ \\
\hline NRLOANS & 0.08420 & $12.23^{* * *}$ & 0.2698 & $14.41^{* * *}$ \\
\hline LIMUTIL & -0.007746 & $-17.72^{* * *}$ & -0.01197 & $-12.91^{* * *}$ \\
\hline COAPPLIC & 0.1300 & $3.83^{* * *}$ & 0.4374 & $4.50^{* * *}$ \\
\hline LOANSIZE & - & - & -0.006637 & -0.98 \\
\hline$\rho$ & - & - & -0.9234 & $-17.34^{* * *}$ \\
\hline
\end{tabular}

The coefficient estimates correspond to the parameters of model (1).

${ }^{*},{ }^{* *},{ }^{* * *}$ represent significance at the $10 \%, 5 \%$ and $1 \%$ level.

of default but have a large positive (negative) weight in the decision to grant a loan. ${ }^{8}$ Possibly, disregarding rejected applicants and building a selection process based on simple correlations (instead of a partial correlation from a bivariate probit) has lead to incorrect inferences about the effect that some variables have on default risk. Table 3 shows, for example, that higher INCOME would then appear to be associated with lower default risk - as it is popularly assumed - whereas the empirical evidence in Table 5 points in the opposite direction. ${ }^{9}$

Finally, it should be noticed that LOANSIZE has no significant influence on default risk. At the margin, an additional loan within the (sample) range of 3000 30,000 SEK does not affect default risk. Given the relatively small LOANSIZE in our sample and the fact that the total amount of credit facilities is between six and seven times as big on average, it is not surprising that LIMIT has most explanatory power. One should therefore be careful not to generalize this result to other

\footnotetext{
${ }^{8}$ Strong correlation between the variables BALANCE and LIMIT tended to create numerical problems when trying to use both as explanatory variables. Some test regressions indicated that LIMIT and BALANCE have opposite effects on the default probability, the former a negative and the latter a positive. The coefficient on LIMIT in Table 4 is approximately equal to the net effect of LIMIT minus BALANCE.

${ }^{9}$ Such a simple correlation may result, for example, if people with higher income happen to have other characteristics that are associated with higher default risk.
} 


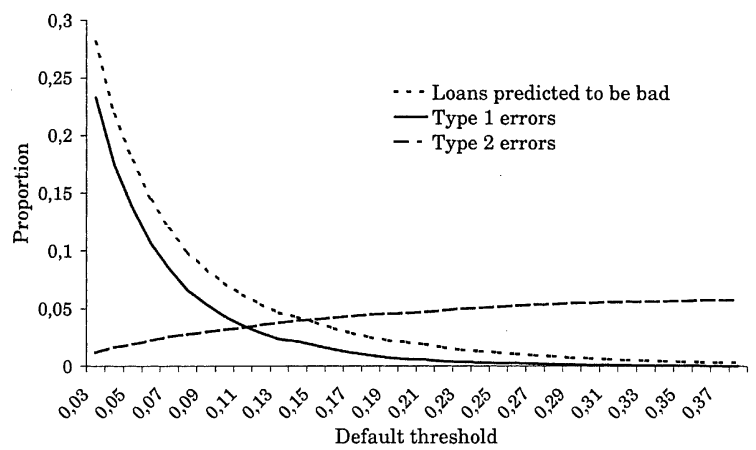

Fig. 1. The Type 1 and Type 2 errors, and the proportion of granted loans that the model predicts to default, as a function of default threshold.

contexts, where the ratio of LOANSIZE to LIMIT is closer to one. Nevertheless, the results do show that with respect to smaller consumer loans, size does not affect the loan's risk profile. Altogether, this suggests that with respect to its consumer credit business the bank has not used all available information and thus that its credit policy has not been consistent with default-risk minimization.

The correlation coefficient takes the value -0.9234 , which implies that non-systematic tendencies to grant loans are almost perfectly correlated with non-systematic increases in default risk. ${ }^{10}$ In other words, the subjective elements - that conflict with the systematic policy described by the first equation in (1) - in the bank's lending policy that increase individuals' odds of being granted a loan, are positively related to increases in default risk that cannot be explained by a systematic relation with the covariates $\mathbf{x}_{2 i}$.

Although the $t$-statistics for most coefficients in Table 5 indicate precise estimates, some additional analyses can be done to investigate the sensitivity of the estimated model. An important characteristic is the model's goodness of fit. Unfortunately, no $R^{2}$-type measures for bivariate models with discrete dependent variables exist. An alternative criterion, provided as standard output in most statistical packages and commonly applied, is the classification error for in-sample predictions based on a threshold value of 0.5 . Greene (1997) points out that the correct (or optimal) value of this threshold should depend on the balance of the sample (i.e., proportion of bad loans) and the costs of incorrectly classifying a good loan as bad and a bad loan as good. In Fig. 1, the percentage Type 1 and Type 2 errors, that result from different thresholds under the null hypothesis that each loan is good, are presented. For threshold values below 0.05 , the Type 1 errors increase explosively and move to its

\footnotetext{
${ }^{10}$ Although the value of -0.92324 for $\rho$ is quite close to -1 , and more than twice as large as what Boyes et al. (1989) found it to be, this is not a symptom of problems with convergence for the algorithm. The correlation coefficient varied between -0.51 and -0.97 depending on the number and the type of variables employed.
} 
upper bound of $94 \%$ of all loans. For a threshold value of 0.25 the Type 2 errors have approximately reached their limit of $6 \%$ of all loans. Within the interval [0.05-0.25], both error type rates are quite smooth. Therefore, also keeping in mind that the actual default rate is $6 \%$, the model appears to be well suited for application in the empirically relevant threshold zone.

Before looking at Table 5, it is worthwhile to recall a hypothesis in Boyes et al. (1989). After finding that banks lending policy was not risk-minimizing, they suggested that banks pick out loans with a higher default risk (in the sense that granting them was not consistent with their model) because they have higher expected returns. Their hypothesis was that banks actually prefer bigger (not necessarily riskier) loans for the one reason that they offer higher expected earnings. But since Boyes et al. (1989) had no data on the size of loans, and they expected bigger loans to be associated with higher risk, their conclusion was that pursuing a policy that maximizes earnings would necessarily imply (optimally) deviating from risk minimization.

In this paper it is possible to control for LOANSIZE and we can thus shed more light on the possible causes of the risk-return choices made by banks. When studying the results in Table 5, one can make three observations. First, many of the variables that make the bank approve loan applications are not among those that reduce the probability of default. Second, non-systematic tendencies to grant loans are indeed associated with greater default risk. Both observations are in accordance with earlier findings and imply that banks do not minimize default risk. Third, the results show that the size of a loan does not affect default risk. The latter finding leads us to reject the hypothesis that banks tend to grant bigger loans because they are riskier. In fact, LOANSIZE has no significant impact on default risk. Consequently, efficiently pursuing a policy that maximizes return therefore does not require any deviation from risk minimization. Moreover, bank behavior that is not consistent with risk minimization cannot be ascribed to a disregarded relation between loan size and return.

Because all loans in this sample pay the same rate of interest, there remain only two sources of differences in the expected rate of return between loans: survival time - and the amortizations and interest payments that result from it - and the loss rate on bad loans. To get a good forecast of profitability, banks may be evaluating survival and the loss rate simultaneously. In a study of the survival of bank loans Roszbach (1998) finds, however, that loans are not provided in a way that is consistent with survival time maximization. Carling et al. (2001) study the relation between consumer credit duration and profitability. Their results suggest that bank lending policy is not profit-maximizing either. As an alternative, this bank could have been maximizing some other objective than the rate of return on its loan portfolio; for example, the number of customers or lending volume subject to a minimum return constraint, or total profits from a range of financial products. The current organization of information flows in the bank and the degree of co-ordination between different departments does not allow for the pursuit of a composite objective such as the return on a range of products. Most important of all, the alternative objectives suggested above are not in agreement with what the managers from the lending institution reported to us in a series of interviews on the matter. The current policy is to accept or reject loan applications by means of a formal but simple evaluation of 
personal and financial characteristics of the applicant. Given these observations, our results should be interpreted as indicating that the lending institution has not minimized risk.

\section{Lending policies and value-at-risk}

This section shows why portfolio credit risk instead of default risk can be auxiliary in optimizing bank lending policy. Estimating individual default risks is merely of limited help, because the individual risks' linkage with aggregate credit losses is unclear. A better way to measure risk is to weigh individual default risks by value, as one does, for example, in the calculation of VaR. Studying VaR not only enables the financial institution to get a measure of the credit risk present in currently administered loans. It also allows for an evaluation of the impact of different lending policies on (a specific measure of) risk exposure and creates a better basis for an explicit decision on the implied loss rate. Hence we derive a VaR-measure using a Monte-Carlo simulation of the bivariate probit model of Section 3. After that, we show how it can be applied to a typical problem that a lending institution is confronted with when supplying loans.

At this point we would like to point out two possible limitations of the subsequent analyses. First, the usefulness of the VaR-measure for policy formation hinges on the banks' objectives. If these include features such as cross-product subsidization, then clearly our proposed VaR-analysis will not be a sufficient basis for policy decisions. Second, the choice of default definition matters for the VaR-measure. Our definition, non-performing loans submitted to a debt-collecting agency, will overestimate actual losses if the agency manages to collect any of the debts at all. However, it is in principle straightforward to correct for this bias by conditioning on information from the debt-collecting agency.

The VaR measure used here is defined as "the loss that is expected to be exceeded with a probability of only $x \%$ during some specified average holding period of $\tau$ days of the loans in the portfolio for which the measure applies". The risk measure $x$ needs to be chosen in advance. As an example, if one sets $x$ equal to $5 \%$ and $\tau$ to 365 days, then a VaR of SEK 10 million ( $\$ 1$ million) means that total credit losses on the loan portfolio will be greater than SEK 10 million within the next 365 days with a probability of $5 \%$. For this application the average holding period, and hence the time horizon of the VaR-measure, is 619 days. ${ }^{11} \mathrm{~A}$ shorter time horizon is of course feasible by considering an earlier monitoring date and a re-estimation of the bivariate probit. In practice, a bank would presumably monitor a portfolio on a regular basis and calculate $\mathrm{VaR}$ estimates for a range of time horizons. Such a procedure allows for simple backtesting of the appropriateness of the VaR measure.

\footnotetext{
${ }^{11}$ For each loan the number of calendar days was calculated between the application date and the monitoring date.
} 
Two experiments are carried out here. First, it will be analyzed how the VaR is affected by marginal changes in the bank's acceptance rule, i.e., the threshold value of default risk above which an applicant is rejected. Second, a hypothetical portfolio of loans, that would be granted if the bank had an acceptance rule based on the bivariate probit at hand instead of its current lending policy, is constructed. Comparing the distribution of credit losses on this hypothetical portfolio with those on the actual portfolio gives us an estimate of the efficiency losses that the bank's lending generates.

In the first experiment we study how the bank can affect its VaR exposure by making its acceptance criterion more or less restrictive. Here, we abandon the bank's current lending policy, as described by the first Eqs. (1) and (2). In Section 3, it was shown that this policy is not consistent with risk minimization. Instead, we construct a default-risk-based acceptance rule of the form

$$
\left.\begin{array}{l}
\text { loan not granted } \\
\text { loan granted }
\end{array}\right\} \text { if }\left\{\begin{array}{l}
\operatorname{pr}\left(y_{2 i}=0\right) \geqslant \delta^{\prime}, \\
\operatorname{pr}\left(y_{2 i}=0\right)<\delta^{\prime} .
\end{array}\right.
$$

By means of a Monte-Carlo simulation similar to the one described above, we can derive the probability distribution of bank credit losses associated with the acceptance/rejection rule (6) for any value of the threshold parameter $\delta^{\prime}$. The Monte-Carlo simulation consists of the following five steps:

1. Pick a value for $\delta^{\prime}$.

2. Draw one observation $\mathbf{x}_{2 i} \widetilde{\boldsymbol{\alpha}}_{2}$ from $N\left(\mathbf{x}_{2 i} \widehat{\boldsymbol{\alpha}}_{2}, \sigma_{\mathbf{x}_{2 i}} \widehat{\boldsymbol{\alpha}}_{2}\right)$ for $i=1,2, \ldots, 13,338$, where $\sigma_{\mathbf{x}_{2 i} \cdot \tilde{\alpha}_{2 i}}^{2}=\mathbf{x}_{2 i} \cdot \Sigma_{\widehat{\alpha_{2}}} \cdot \mathbf{x}_{2 i}^{\prime}$. Number them $i=1,2, \ldots, 13,338$

3. To determine which applicants will be granted a loan, calculate the expected default probabilities $E\left[\operatorname{pr}\left(y_{2 i}=0\right)\right]$ as

$$
E\left[\widetilde{p}_{i}\right]=1-\Phi\left(\mathbf{x}_{2 i} \cdot \widetilde{\boldsymbol{\alpha}_{2 i}} /\left(1+\sigma_{\mathbf{x}_{2 i} \cdot \tilde{\alpha_{2 i}}}^{2}\right)^{1 / 2}\right)
$$

and then apply (6). Number the approved applications $i=1,2, \ldots, N_{\mathrm{A}}$.

4. For the $N_{\mathrm{A}}$ approved applications, compute the total credit losses $\lambda$ on this portfolio as

$$
\lambda=\sum_{i=1}^{N_{\mathrm{A}}} E\left[\widetilde{p}_{i}\right] \cdot q_{i}
$$

where $q_{i}$ is the size of the loan individual $i$ applied for. Because $q_{i}$ is not available for the rejected applicants, we impute $\bar{q}=\frac{1}{N_{\mathrm{A} \text {,true }}} \sum_{i=1}^{N_{\mathrm{A} \text {,true }}} q_{i}$ in steps $1-4$. Here, $N_{\mathrm{A} \text {,true }}$ is the number of accepted applicants in the original sample.

5. Repeat steps 1-4 $M$ times and compute the approximate probability distribution over losses from the $M$ values one obtains for $\lambda$. $M$ should be chosen such that the distribution of $\lambda$ is invariable for $M^{\prime} \geqslant M$. We take $M=100.000$.

For this purpose we have picked a series of values $\delta^{\prime}$ in the interval $[0.01,0.20]$. The results from these simulations are displayed in Table 6 . The second column of 
Table 6 shows how expected loan losses increase as the bank relaxes its lending policy. The most restrictive policy, $\delta^{\prime}=0.01$, results in lending between 36.6 million and 37.2 million kronor, whereas the most generous policy, $\delta^{\prime}=0.20$, leads to approximately two and a half times as much lending. As the lending volume grows, losses increase at an accelerating rate. For the most risk averse decision rule loan losses range from 0.3 to 0.6 million kronor, compared to SEK 3 million-up to 9 times as much - on the riskiest loan portfolio. As expected the loss rate, loan losses divided by total lending, rises from $0.36 \%$ to $3.35 \%$ as the acceptance criterion $\delta$ is successively relaxed from 0.01 to 0.20 . Total losses and the loss rate both monotonically increase with $\delta$, at an ever decreasing rate however.

Applying a VaR analysis before selecting a lending policy thus allows the lending institution to decide explicitly on either its aggregate credit risk exposure or its loss rate. Alternatively, it could choose to pick a desirable loss rate conditional on the VaR not exceeding some maximum allowable amount of money. Doing so has several advantages. First, compared to current practice, the risk involved in lending becomes more transparent. Instead of registering loans that have already become non-performing, the financial institution will be able to create provisions for future losses. This offers gains from both a private (bank) and a social perspective. From a private perspective because provisions for loan losses on banks' balance sheets will be forward-looking and only lag unexpected events, i.e., events associated with outcomes beyond the chosen VaR-percentile in the loan-loss distribution. This should

Table 6

$95 \%$ confidence intervals for total loan losses, total lending (both in $1000 \mathrm{SEK}$ ) and the loss rate (total credit losses/total lending), all for given rejection threshold $\delta^{\prime}$

\begin{tabular}{llll}
\hline$\delta^{\prime}$ & Loan losses & Total lending & Loss rate \\
\hline 0.01 & $131-137$ & $36,583-37,226$ & $0.36-0.37$ \\
0.02 & $339-551$ & $51,124-51,763$ & $0.66-0.68$ \\
0.03 & $548-564$ & $59,705-60,318$ & $0.92-0.94$ \\
0.04 & $751-773$ & $65,641-66,248$ & $1.14-1.17$ \\
0.05 & $948-947$ & $70,083-70,683$ & $1.35-1.38$ \\
0.06 & $1143-1174$ & $73,678-74,276$ & $1.55-1.58$ \\
0.07 & $1334-1370$ & $76,672-77,225$ & $1.74-1.77$ \\
0.08 & $1516-1555$ & $79,138-79,703$ & $1.91-1.95$ \\
0.09 & $1687-1730$ & $81,181-81,730$ & $2.08-2.12$ \\
0.10 & $1849-1895$ & $82,916-83,449$ & $2.23-2.27$ \\
0.11 & $2003-2053$ & $84,411-84,923$ & $2.37-2.42$ \\
0.12 & $2149-2201$ & $85,699-86,190$ & $2.51-2.55$ \\
0.13 & $2285-2339$ & $86,812-87,279$ & $2.63-2.68$ \\
0.14 & $2414-2470$ & $87,785-88,230$ & $2.75-2.80$ \\
0.15 & $2285-2339$ & $88,641-89,066$ & $2.85-2.91$ \\
0.16 & $2648-2709$ & $89,389-89,793$ & $2.96-3.02$ \\
0.17 & $2752-2814$ & $90,034-90,416$ & $3.06-3.11$ \\
0.18 & $2847-2909$ & $90,586-90,945$ & $3.14-3.20$ \\
0.19 & $2932-2995$ & $91,057-91,398$ & $3.22-3.28$ \\
0.20 & $3009-3073$ & $91,467-91,789$ & $3.29-3.35$ \\
\hline
\end{tabular}


Table 7

VaR at different risk levels computed for the sample portfolio and an efficiently provided portfolio of equal size (amounts $\times$ thousand SEK)

\begin{tabular}{llll}
\hline Portfolio & \multicolumn{3}{l}{ Risk level $(\%)$} \\
\cline { 2 - 4 } & 1 & 5 & 10 \\
\hline Sample & 1513 & 1506 & 1503 \\
Efficient & 263 & 262 & 261 \\
\hline
\end{tabular}

facilitate a more efficient allocation of resources and a more accurate evaluation of the bank. At an aggregate level, there would be less risk of bankruptcy of financial institutions and therefore less risk of financial disturbances to the economy. ${ }^{12}$ (See for example Bernanke and Gertler (1995).) Secondly, unless the bank sets interest rates individually, this methodology also enables a bank to pick a risk-premium on top of the risk free rate of interest that is consistent with average credit risk over the maturity in question. If the loss rate is $2.5 \%$, for example, and the average duration of a loan is three years, then the bank could charge a risk-premium of approximately $0.8 \%$ per annum.

The aim of the second experiment is to produce an estimate of the monetary losses that the inefficiency in the current lending policy gives rise to. Table 6 has already given an impression of how lending volume, loan losses and the loss rate co-vary, and can help a bank choose one specific efficient lending policy from a larger set. However, before switching to a new policy, a financial institution will first want to quantify the potential gains from doing so. For this purpose, we construct the "efficient portfolio" of loans that would be granted if the bank used a default-risk-based decision rule, instead of its current policy, but preferred a lending volume (approximately) equal to that of the actual portfolio. Executing steps $1-3$ in the above Monte-Carlo experiment and picking $\delta^{\prime}$ such that the simulated lending volume equals actual lending gives us the desired portfolio.

By inspecting Table 6 one can readily infer that the implied value of $\delta^{\prime}$ will lie between 0.01 and 0.02 . We find that $\delta^{\prime}$ equals 0.012 . We then repeat steps $2-5$ of the Monte-Carlo experiment for both the actual and the "efficient portfolio"-but do not apply (6) in step 3 since we already know which individuals make up our sample. From the credit-loss distributions that are obtained along these lines, we extract three different VaR measures for each portfolio.

These are displayed in Table 7. Credit losses on the two portfolios clearly differ greatly. At the $10 \%$ risk level, the VaR amounts to SEK 1503 thousand for the actual portfolio compared to 261 thousand for the efficient portfolio. At the $1 \%$ risk level these amounts are 1513 and 263 respectively. By shifting to a default-risk-based

\footnotetext{
${ }^{12}$ In June 1999, Basel Committee on Banking Supervision (1999) released a proposal for the revision of the international capital accord suggesting that banks required capital should reflect their actual credit risks to a larger extent than under the current accord. Our suggested measure of consumer credit portfolio risk constitues a basis for the determining the level of required capital in the spirit of the Basel Committee proposal.
} 
decision rule and abandoning its current lending policy, the bank can reduce its expected credit losses significantly. Continuing providing loans in the same way as has been done leads to a VaR exposure that is six times higher than for a policy consistent with default-risk minimization. Switching to one of the "efficient" lending policies displayed in Table 6 thus involves large potential benefits for the financial institution.

\section{Discussion}

In this paper the bivariate probit model has been applied to investigate the implications of bank lending policy. From an extensive data set evidence is found that banks provide loans in a way that may not be consistent with default-risk minimization. Earlier research has suggested that banks prefer bigger loans because they offer higher expected earnings. Since, controlling for other counterparty characteristics such as total income or total assets, bigger loans are generally thought to be riskier, maximizing expected earnings would then imply deviating from risk minimization. However, with the data on the size of all loans that we have at our disposal, size has been shown not to affect the default risk associated with a loan. The bank, even if it is risk-averse, is thus not faced with a trade-off between risk and return. Thus, the inconsistency in banking behavior cannot, at least not for the case of small revolving loans analyzed in this study, be ascribed to some relation between loan size and return, that earlier models had not accounted for. This suggests that the bank's behavior is either a symptom of an inefficient lending policy or the result of some other type of optimizing behavior. Banks may, for example, be forecasting survival time, or loss rates, or both. Another possibility is that they are maximizing another objective than the rate of return on their loan portfolio, e.g., the number of customers, lending volume subject to a minimum return constraint, or total profits from a range of financial products. Current banking technology does not yet allow for the pursuit of a composite objective such as the return on a range of products, however. In addition, the above suggestions are not in agreement with the practices reported to us by the lending institution that provided our data. Except for rejecting applicants that are too risky, the lending institution has no explicit credit policy. For this purpose, employees who decide if loan applications should be granted or rejected, examine part of the personal information that is available from the credit agency; except for the total exposure at the institution, they do not dispose of any information whatsoever about either the (historical or expected) return on a loan or the range of products that an applicant already obtains at the lending institition. Our findings thus bear the evidence of a lending institution that has neither minimized credit risk nor maximized the rate of return, but practice a simple decision-rule scheme.

VaR, being derived from a value-weighted sum of all predicted individual risks, provides a measure of the expected monetary losses on a portfolio of loans. Naturally, the appropriateness of this measure depends on the relevance of the chosen definition of default. Our definition, non-performing loans submitted to a debt-collecting 
agency, can be expected to exaggerate actual losses, should the bank be able to retrieve some of its debts.

By means of Monte-Carlo simulation with the estimated bivariate probit model, we propose a $\mathrm{VaR}$ measure for the sample portfolio of loans. We also show how calculating VaR can enable financial institutions to evaluate alternative lending policies on the basis of their implied credit risks and loss rates. The methods suggested here can in principal be generalized to the case of commercial loan portfolios, although the greater heterogeneity of such portfolios compared with retail loan portfolios implies that the modelling exercise will be more demanding.

An analysis of the VaR involved in lending policies offers both private and social gains. Provisions for loan losses on banks' balance sheets will become more forwardlooking. At an aggregate level, the risk of bankruptcy for financial institutions and the likelihood of financial disturbances to the economy would be reduced. Banks would also be able to choose a risk-premium on top of the risk free rate of interest that is consistent with average credit risk over the maturity in question. One possible limitation for a VaR-based lending policy arises if the bank strives towards other objectives than risk-minimization or rate of return-maximization, such as a composite objective including, e.g., cross-product subsidization. Another limitation is that the choice of default definition matters for the VaR-measure.

\section{Acknowledgements}

We thank Georgina Bermann, Kenneth Carling, Dennis Hoffman, Sune Karlsson and Anders Vredin for their helpful comments and Björn Karlsson and Yngve Karlsson at Upplysningscentralen AB for providing and discussing the data. Suggestions from two anonymous referees improved the paper considerably. Kasper Roszbach gratefully acknowledges financial support from the Jan Wallanders and Tom Hedelius Foundation for Research in the Social Sciences.

\section{References}

Basel Committee on Banking Supervision, 1999. A New Capital Adequacy Framework, Publication no. 50, June 1999. http://www.bis.org/publ/index.htm.

Bernanke, B., Gertler, M., 1995. Inside the black box: The credit channel of monetary policy transmission. Journal of Economic Perspectives 9 (4), 27-48.

Boyes, W.J., Hoffman, D.L., Low, S.A., 1989. An econometric analysis of the bank credit scoring problem. Journal of Econometrics 40, 3-14.

Carling, K., Jacobson, T., Roszbach, K.F., 2001. Dormancy risk and expected profits of consumer loans. Journal of Banking and Finance 25, 717-739.

Greene, W.E., 1997. Econometric Analysis, third ed. Prentice Hall, Englewood Cliffs, NJ.

Jaffee, D., Stiglitz, J.E., 1990. Credit rationing. In: Friedman, B.M., Hahn, F.H. (Eds.), Handbook of Monetary Economics, vol. 2. North-Holland, Amsterdam, pp. 837-888.

Roszbach, K.F., 1998. Bank lending policy, credit scoring and the survival of loans. Working Paper Series in Economics and Finance No. 261, Stockholm School of Economics. http://www.hhs.se. 
Stiglitz, J.E., Weiss, A., 1981. Credit rationing in markets with imperfect information. American Economic Review 71, 393-410.

Williamson, S., 1987. Costly monitoring, loan contracts and equilibrium credit rationing. Quarterly Journal of Economics 102 (1), 135-145. 